\title{
Phonological, Grammatical and Semantic Deviations in the Lyrics of Kabhanti
}

\author{
Aderlaepe $^{1}$, Tambunan ${ }^{2}$ \\ \{laino@uho.ac.id ${ }^{1}$, laode@uho.ac.id ${ }^{2}$ \} \\ ${ }^{12}$ Halu oleo University Kendari, Sulawesi Tenggara, Indonesia
}

\begin{abstract}
The usingof aesthetic and artificial language in oral traditional verse sometimes exceeds its functions as a medium to convey morality advice, character building, self emotional expression, and embeded wishes. As atraditional verse, lyrics of kabhanti are created by using marvellous language that potentially disturbs to understand the messages. Language style of kabhanti is perceived strange as the impact of linguistic deviations to achieve the sense of aesthetic. This study aims at describing and analyzing phonological, grammatical, and semantic deviations as the means to achieve the sense of aesthetic in the lyrics of kabhanti. The study is designed descriptive qualitatively by adopting Leech's theory (1969) and applying a contrastive analysis. Data of kabhanti lyrics were taken from the people who had adequate experiences to perform kabhanti in front of audience. Results of the study are phonological deviation is achieved by phonemic addition at the beginning and middle of words through phonemic appearing of nasal alveolar of $\mathrm{n} / \mathrm{n} /$, nasal velar of $\mathrm{ng} / \mathrm{h} /$, and fricative velar of $\mathrm{m} / \mathrm{m} /$; grammatical deviation by inversion; and semantic deviation by transference and honest deception. Transference occurs through the using of figurative languages of metaphor, synecdoche, and metonymy; honest deception by the using of litotes, hyperbole, and irony. The three kinds of deviations make the language style of kabhanti becomes more aesthetic and artistic compared to the conventional syle of daily language
\end{abstract}

Keywords - Aestheticsense, kabhanti, linguistic deviation, people of Munanese

\section{Introduction}

Kabhanti is one of three Munanese folksongs besides lagungkodau and kau-kaudara [1]. It is a two or a four-line traditional verse that expressed orally by being chanted.A two-line kabhanti is the one whose lyric consists of two lines, both of the lines are contents or messages. The other one, the four-linekabhanti has four lines lyric, the first two lines are introduction and the second two lines are the contents or messages. Kabhanti is chanted in metric rhythm with medium tempo resembling country song. Lyrics of kabhanti are short and simple, but however 
the expression of meaning in the lyrics is represented. Due to the simplicity of the lyrics, wordschoice in kabhanti lyrics are really selective to convey the meaning or message.

The ethnic groups who express kabhanti are the people of Munanese and Butonese. Both of the ethnic groups are local indigenous people in South East Sulawesi Indonesia, besides Tolakinese and Moronenese. People of Butonese live in Butonisland and Wakatobi (Wanci, Kaledupa, Tomia, and Binongko) archipelago. People of Munanese inhibit Munaisland that administratively is Muna regency, Province of South East Sulawesi. Type of kabhanti as the object of this study is the one that expressed by the people of Munanese especially the two-line ones The people of Munanese chant kabhanti in daily life as well as in kabhanti performance. Thereby Aderlaepe [2] classifies kabhanti by status into two kinds, kabhanti as a folksong and kabhanti as a reciprocal song. The first oneis chanted in daily life, whereas the second one is chanted reciprocally by two groups (men and women) on a stage during a performance of kabhantiin front of audience. This classification is based on Finnegan's argument that there are three orality elements of oral poetry, they are (1) composition, (2) transmition, and (3) performance [3]. Composition is a creating process, whereas transmition is a process which the oral poetry spreads out in community members, and performance is an activity to perform the oral poetry in front of audience. Kabhanti as a reciprocal song is the one which the composition and performance aspects occur in the same time. Lyrics of kabhanti arecomposed during the performance in front of the audience. People in two groups who perform kabhanti compose and chant the lyricsreciprocally on the stage. On the other hand, kabhantias a folksong is not performed in front of audience. It is chanted in daily life while they are working to cultivate garden, rocking child in a cradle, guarding crops from animal attack, feeling sad or disappointed, etc. Lyrics of the folksong had been composed previously and the people keep them in their memories. The lyricswere indeed permanently organized in certain patterns and ready to be expressed orally any time.Ong [4] argues that thinking in an oral culture takes place in mnemonic patterns and shaped for ready oral occurrence.

There are several violations of language rules in the lyrics of kabhanti. Leech [5]distinguishes poetic from ordinary language. He argues that poetic language may violate or deviaterules of the language in many different ways. As a poetic language, the eccentric use of language in the lyrics ofkabhanti is rather different from the conventional daily usage. $\mathrm{Li}$ and Shi [6] states that poetic language usually escapes from the conventional language traditions and avoids the common every day language.

This study is a stylistic one. Verdonk [7] views stylistic as a study of language style, it is an analysis of specific expression of language to describe certain objective and effect. The specific expression of language according to Teeuw [8]is a characteristic of literary language that usually deviates from daily usage or from the standard norms. It means the language that is used in literary work is rather different form the one that is used in daily communication or in non litetary work. Related to this phenomenon, stylistic study is needed to analyze literary language that is different from the non-literary one [9].

The uniqueness of literary language especially poetry is purposely designed by poets to achieve aesthetic values in their works. To achieve the aesthetic impression, poets deviate language norms graphologically, phonologically, syntactically, or semantically. Certainly the language style they use is perceived more artistic than the conventional one, but the consequent is the presence of constraint in comprehending their poems. By analyzing language deviation in poems, one contributes make the poems as literary works be more easily to be comprehended.

Lyrics of kabhanti as oral verse are composed by using artificial and aesthetic language. Phonological, grammatical and semantic deviations in the lyrics of kabhanti are the means to achieve artificial and aesthetic language, but they obscure the meaning or message that conveyed in the lyrics. On the other hand, kabhanti functions as a medium of communication to state morality advice and character building [10]. Therefore, by analyzing phonological, 
grammatical, and semantic deviations in the lyrics of kabhanti, the messages of kabhanti are more easily comprehended.

A. Theoretical Frameworks

Leech [11] devides linguistic deviation into eight categories, they are (1) phonological, (2) graphological, (3) lexical, (4) grammatical, (5) semantic, (6) dialectal, (7) deviation of register, and (8) deviation of historical periodic.These deviation categories are elaborated from three parts of language anatomy: realization, form, and meaning (semantics). Realization is devided into spoken language (phonology) and written language (graphology). Form comprises grammar and lexicon; and meaning (semantics) deals with denotative or cognitive meaning. Thereby, Xueyong [12] argues the analysis of languagein specific usage can be done inrealization, form, and semantic.

Phonological deviationoccurs in pronunciation which is done deliberately in regard to preserving the rhyme. It is identified by the existence of a mispronounced words or phrase, as if it is a new one but not really, since the speaker moves away from the normal manner of sound. Jones [13] classifiesphonological deviationinto aphesis(the omission of an initial part of a word), syncope(the omission of a middle part of a word), and apocope (the omission of a final part of a word). But in the lyrics of kabhanti show contrarily, it is not omission of word part, but a phonemic addition. There is a certain phoneme appears at initial and middle of words.

Grammatical deviation is a kind of deviation that breaks the rules of grammar which can take place in the level of morphology or syntax. It takes place since the poet disregards the rules of sentence or syntactic features [14]. In the level of morphology, the deviation is varied. It is mostly found in morphological process (affixation, compounding, morphemic deletion, and morphemic addition). Meanwhile, in the level of syntax the deviation can be found in incorrect grammar or syntactic rearrangement/hyperbaton.

Semantic deviation is the most significant level of linguistic deviation in poetry since figurative language is the heart of poetry [6]. It is deemed as absurdity or non- sense in stating the meaning. It is achieved through the using of figurative languages. Leech [11] asserts semantic deviation as an important poetic language that presents in all great poems.He divides semantic deviation into semantic oddity, transference, and honest deception. Semantic oddity is achieved by the using of pleonasm, periphrases, tautology, oxymoron, and paradox. The aspect of transference deals with the use of metaphor, synecdoche, and metonymy; while honest deception is the use of hyperbole, litotes, and irony.

Since kabhanti is oral verse (oral poetry), model of the realization is only phonology concerns with the pronounciation of phonemes, words, or phrases as language units built the lyrics. Related to the three deviations as the focus of the study, phonological deviation is the mispronounced phonemes exist in the lyrics. Grammatical deviation is the use of ungrammatical clause or sentence in the lyrics. The last one, semantic deviation relates to the use of figurative languages in conveying the meaning or message.

B. Related Study

All scholars who had done stylistic study to explore linguistic deviation in literary works adopted Leech's theory. The writers present five related studies in this part, done by FathuRahman and SukardiWeda (2019); Sohaila Abbas and SardarBahardur Khan (2017); Xi Li and Mengchen Shi (2015); Prafitri andSuhatmady (2014); and SukasihRatnaWidayanti (2014).

FathuRahman and SukardiWeda (2019) investigated Linguistic deviation and rhetoric figures in ten Shakespeare's plays. They inventoried a number of linguistic deviations and rhetoric styles, and determined to what extent of non- native English respondents failed to understand the linguistic deviation in Shakespeare's works. They found that linguistic deviation and rhetoric syles in Shakespeare's plays are (1) deviation of syntax in sentence order, Shakespeare sometimes uses sentence with pattern of OSV that breaks conventional English language rule of sentence pattern of SVO; (2) hypallage, combining two examples of 
hyperbaton and anastrophe; (3)aphaeresis, rhetorically deleting a syllable; (4)apocope, to delete a syllable or a letter from the end of a word; (5) polyptoton, a rhetorical figure that consist of two verb forms; (6) neologism, the using of certain word a lot that are rarely found in English language today; and (7) paranomasia, a mere accidental phonetic relationship assume to appearance a semantic relationship. Related to the difficulty of 30 respondents students of Literature in English Language Studies (ELS) Department, Faculty of Cultural SciencesHasanuddin University in reading Shakespeare's plays, 68,4\% were disturbed by linguistic deviations. However, the results of their study are considered being useful to the students to overcome their problem of limit understanding when they read the scripts of the plays.

Sohaila Abbas and SardarBahardur Khan (2017) explored the types of linguistics deviations and the reasons for the usage of linguistic deviations by the poet P. B. Shelley in his poem Adonais. By using Leech's classification of linguistic deviation, Abbas and Khan found there were six linguistic deviations in the poem of Adonais: lexical, phonological, grammatical, graphological, semantic, and historical period deviations. P.B. Shelly, the poet of Adonais used the six typed of deviations for abrogating the regular grammatical and syntactic rules, enhancing aesthetic sense and express certain emotions, also creating new words.

$\mathrm{Xi} \mathrm{Li} \mathrm{and} \mathrm{Mengchen} \mathrm{Shi} \mathrm{(2015)} \mathrm{took} \mathrm{stylistic} \mathrm{study} \mathrm{on} \mathrm{linguistic} \mathrm{deviation} \mathrm{in} \mathrm{twelve} \mathrm{E.E.}$ Cumming's poetries. They explored foreground effect and aesthetic values of the poetries realized through linguistic deveations. Foreground is the deviation from linguistic or other socially accepted norms. By applying Leech's theory and Xueyong'sthee-dimensional model and frame work, they found that linguistic deviations in twelve selected Cumming's poetries reflect intense affection, internal happiness, pain, struggle, sense of humor, and penetrating satire. Wilma Prafitri andBibitSuhatmady (2014) analyzedthe existence and contribution of semantic deviation on the eight William Blake's Poems. Asresults of their study, they revealed semantic deviation in the poems that was formed by three tropes: semantic oddity, transference of meaning, and honest deception. Contribution of the deviation that purposely done by William Blake makes his poems more aesthetic, also as a medium to transmit his point of view about social condition, religious values, love, and human to huma relationship.

SukasihRatnaWidayanti (2014) inventoried and described language deviation in Thomas Hardy's poem, The Ruined Maid. By using Leech's classification of linguistic deviation as a patron, Widayanti found there were five deviations: lexical, grammatical, graphological, semantic, and historical deviations.

C. Objective of the Study

Since the major deviations occur in the lyrics of kabhanti deals with pronounciation, grammar, and diction to state the meaning, this study is emphasized the concentration on three categories: phonological, grammatical, and semantic deviations. Therefore the objectives of this study is: to analyze, describe, and explain the purposely breaking linguistic norms of Muna language in the lyrics of kabhanti on phonology, grammatical, and semantic aspects that makethe lyrics are more aesthetic than the conventional one. Hopefully results of this study contribute to the comprehension of meaning to those who listen to kabhantisongs.

\section{Methods}

This stylistic study is designed descriptive qualitatively. Data of the study were taken based on their natural condition, then described and analyzed based on their natural characteristics. In analyzing data, the writers apply objective approach. Abrams [15] asserts that in analysis of stylistic study,the approach is objective one. The objective approach emphasizes interrelationship of intrinsic elements built the literary work. Aminuddin [16] argues that 
stylistic study uses objective approach because target of the analysis is focused on the using of the system of sign in literary work.

However this study needs adequate linguistic knowledge and pragmatic competence in Muna language since the lyrics of kabhanti are composed in Muna language. Wellek and Warren [17] asserts that stylistic study in literary language cannot be conducted well without having sufficient linguistic knowledge since the main emphasize of the study is the contrastive of literary language system and conventional daily language usage. Therefore in analyzing data, the writers applied a contrastive analysis. The using of language in the lyrics of kabhanti is contrastedor compared to the languagerules of Muna language of standard dialect. The analysis is based on the language rules as a standard framework. Berg [18] classifies geographical variation of Muna language into three dialects: standard, tiworo, and southern Muna dialects. The using of standard dialect is the most widely spreaded that extends from Northern of Muna island to Tongkuno district at the Southern part of Muna regency.

Data were taken from informants through observation, interview, noting, and recording. The informants were the members of Munanese community who had adequate experience in performing kabhanti in front of aundience. Data of phonological deviation are the mispronounced phonemes exist in the lyrics of kabhanti. Data of grammatical deviation are the ungrammatical expressions exist in the lyrics, whereas data of semantic deviation are the using of figurative languages in conveying the meaning. In determining the mispronounced phonemes or morphemes and the ungrammatical expressions, the writer used the system (pronunciation and grammatical systems) of Muna language of standard dialect.As a native speaker of Muna language standard dialect, the writers has lexical, grammatical, and pragmatic competences in Muna language. Chomsky [19] asserts that a native speaker of a certain language has the three competences naturally through language acquisition process. Lexical competence relates to the ability of using correct diction (words) to state something, grammatical competence is the mastering of grammatical rules of language both in morphological and syntactical level, whereas pragmatic competence is the ability to use language based on the context and situation.

\section{Results and Discussion}

Lyrics of kabhanti are short and simple, not more than ten syllables, mostly eight syllables. Although the lyrics are simple, the meanings or messages somehow are represented. It is because Muna language is a morphosyntax one. Verb and adjective can not stand alone independently as free constituents, they are always attached by sentence elements whether subject or object. Kridalaksana (1984:129) in his Linguistic dictionary defines morphosyntax is a language structure scopes morphology and syntax as unseparated organization. The morphological constituent of word contains sentence elements, may be subject or object, or may be complement.

Sentence in Muna language (includes the one used in kabhanti lyrics) obliges the presence of subject on the constituent of predicate. It is different from English language where the predicate of sentence is always filled by verb. Predicate of sentence in Muna language can be filled by verb, adjective, noun, numeral, or preposition. The presence of subject that attaches in the predicate of sentence is obligatory. On the other hand, subject as a free constituent at the beginning of sentence is optional, can be omitted and can be maintained.

D. Phonological Deviation in the Lyrics of Kabhanti

Phonological deviation is a kind of linguistic deviation in pronounciation. It is identified by the existence of mispronaunced phonemes in the lyrics of kabhanti. The mispronounciation is actually occur purposefully to make the lyrics be more aesthetic. However aesthetic in literary 
work particularly poetry is a priority element [20]. Consequently the attempt causes the lyrics are heared rather strange, but become more aesthetic.

The mispronounced phonemes in the lyrics of kabhanti are achieved through phonemic addition, by the appearing of nasal alveolar phoneme of $n / \mathrm{n} /$, nasal velar of $n g / \mathrm{h} /$, and fricative alveolar of $m / \mathrm{m} /$. In daily communication, such phonemic addition does not occur. Pay attention to the lyrics of kabhanti bellow.
1. Anepaekosabara Dhuniantaweanemo
"If (you) do not have patience"
2. Sabarasehaensoda Mbiritatainodimo "The world remains embers" Sapaenoomensuru
"The patience how much can (I) endure"
"The spreaded out news is only me" "If you do not stand forever" Amabhikongkuralalo "I'll call you the less heart"
4. Lalohae so nensuru "What kind of heart makes stand forever " Sandaranontiwuramo "The prop is already seen"

Kabhanti number (1) above, phoneme of $n / \mathrm{D} /$ appears at the second line. In daily communication, there is no phoneme of $\mathrm{n} / \mathrm{n} /$ at the beginning of $t a$ 'remains', so the sentence is Dhunia ta weanomo'the world remains embers'. Certainly the sentence of Dhuniantaweanomo is more asthetic and more artistic than the other one Dhunia ta weanomo.

Kabhanti number (2) also accurs phonemic appearing of $n / \mathrm{n} /$ at the first line and phonemic appearing of $m$ at the second line. The word of $n$ soda at the firt line is derived from soda 'endure'. The word of mbirita'news' at the second line is derived from birita 'news'. This phenomenon is also a phonemic addition through nasalization or appearing nasal and appearing phoneme of $\mathrm{m} / \mathrm{m} /$. At the first line, the sentence of Sabarasehaensoda the patience how much can (I) endur' is more aesthetic than the everyday usage Sabarasehaesoda 'the patience how much can (I) endur'. At the second line, the sentence Mbiritatainodimo"the spreaded out news is only me" is also more aesthetic than the one that is usually used in daily communication: Biritatainodimo"the spreaded out news is only me".

Kabhanti in number (3), there is also a phonemic addition through nasalization. In the first line, the word of omensuru is derived from omesuru 'you stand forever'. Nasal of $\mathrm{n} / \mathrm{n} /$ appears at the middle of omesuru, so becomes omensuru. At the second line, the phoneme that appears is $n g / \mathrm{h} /$ at the beginning of kura 'less', so becomes ngkura 'less'. Consequently the sentence of Amabhikongkuralalo'I will call you the less hear' is perceived more aesthetic than the original one Amabhikokuralalo.

Kabhanti number (4) above also experiences phonemic addition by appearing nasal phoneme of $n / \mathrm{n}$ / at the first and second lines. The word of nensuru 'stand forever' at the first line is derived from nesuru and the word of nontiwuramo 'is already seen' at the second line is derived from notiwuramo. However the word of nensuru 'stand forever'is more asthetics and more artistic than nesuru. The same case, the word of nontiwuramo 'is already seen' is more artistic and aesthetic than notiwuramo. The sentence of Lalohae so nensuru 'what kind of heart makes stand forever' at the first line is more aesthetic and artistic than the original one Lalohae so nesuru. Also the sentence of Sandaranontiwuramo'the prop is already seen' at the second line is more fresh and more aesthetic than the original one Sandaranotiwuramo'the prop is already seen'.

\section{E. Grammatical Deviation in the Lyrics of Kabhanti}

The only one of grammatical deviation found in the lyrics of kabhanti is inversion. The expression of inversion is identified by the sentence order where predicate precedes subject. Sentence order in Muna language is S-P (subject-predicate), but the inversion order is P-S or C$\mathrm{S}$. Inversion sentence is a sentence that the predicate precedes the subject [21].

Grammatical deviation in the form of inversion is not as mush as phonological deviation exist in the lyrics of kabhanti. Pay attention to the examples of inversion sentences bellows.
1. Lalokuamafaane
"My heart how do I make" 


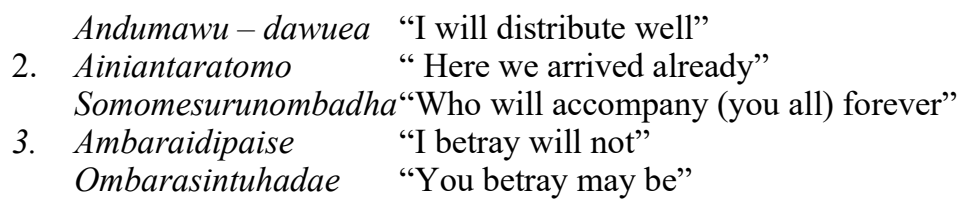

Three kabhanti above use inversion sentences.Kabhanti in number (5), the inversion sentence is found in the first line. Lalokuamafaane 'my heart how do I make' is derived form the original of Amafaanelaloku 'how do I make my heart'. Sentence order of Lalokuamafaane 'my heart how do I make' is $\mathrm{C}-(\mathrm{S}) \mathrm{P}$, where in the constituent of the predicate amafaane presents the subject $a$ as the first person singular. This is one of characteristics of Muna language as a morphosyntax language.

Inversion in kabhantinumber (6) above is also found in the first line. The sentenceAiniantaratomo 'here we arrived already' has pattern C-(S)P. The original every day expression is Ntaratomoainia 'we arrived already here' with the pattern (S)P-C. In the predicate constituent of ntaratomo, there is a subject, it is ta at the beginning of the constituent. Subject $t a$ in this case is the first person plural exclusive.

Kabhanti number (7) above uses two inversions, at the first and second lines. The sentence of Ambaraidipaise 'I betray will not' at the first line has pattern (S)P-S. It is derived from Idi paiseambara 'I will not betray' with the pattern S-(S)P. In the second line, the inversion sentence of ombarasintuhadae 'you betray may be' has pattern (S)P-S-C. It is also derived from the original one that is used in daily communication Sintuhadaeombara 'you may be betray' with the pattern S-(S)P.

The using of inversion in kabhantinumbers (5), (6), and (7) above makes the lyrics ofkabhantiare more fresh and perceived more asthetic. The inversion sentences in the lyrics are more fresh and aesthetic than the conventional sentences. The inversion sentence of lalokuamafaane 'my heat how do I make' in kabhantinumber (5) at the first line is more fresh and more aesthetic than the conventional one that is used in daily communication amafaanelaloku'how do I make my heart'. Such impression also happens to another inversion sentences exist in the lyrics of kabhanti.

F. Semantic deviation in the Lyrics of Kabhanti

Semantic deviation occurs in the lyrics of kabhanti through transference and honest deception. Both of them are realized by the using of figurative languages.

1. Transference

Transference is a means of semantic deviation through the using of figurative languages of metaphor, synecdoche, and metonymy (Li and Shi, 2015:34). Metaphor is a comparison of two different things but they are stated the same, without using explicit sameness: such, likes, as (Nurgiyantoro,1995:299). It means that metaphor is a comparison of two different things implicitly by using a simple sentence. Pay attention to the example bellow.

1. Dhuniangkodhuniano "The world is other's"

Alamungkoalamuno "The cosmos is other's"

Kabhanti in number (8) above is an inner emotional expression that states a complaint. Dhuniangkodhuniano 'the world is other's' in the first line has semantic impressio that "a group of people can do any thing what they want", so they are as if the owner of the world. The subject of I (the singer) who chants the lyric of kabhanti is powerless and can do nothing. In this sentence there is a word that states the sameness, but it is omitted. If it is stated explicitly, the expression is less aesthetic. It is pedamo 'like'. The sentence of Dhuniangkodhuniano 'the world is other's' is more aesthetic than Dhuniapedamongkodhuniano 'the world is like the other's'. The aesthetic value of the second sentence is less than the first one since the word of pedamo 'like' is stated explicitly. The sentence in the second line of kabhanti number (8) above also uses metaphor. Alamungkoalamuno 'the cosmos is the other's' has semantic impression "a group of people do what they want, as if the cosmos is theirs". There is comparison between 
cosmos and the ownership of the cosmos by a group of people who act freely what they want, as if the cosmos is theirs.

Synecdoche is an expression that states a part refers to a whole or states a whole refers to a part. The use of synecdoche in thelyrics of kabhanti can be seen in the example bellow.
1. Tabeametapaane
Lahaetunggunombadha
"Excuse me, (I) ask about it"
"Who is the guard of the body"

The word of mbadha'the body' at the end of the second line in kabhanti number (9) above refers to people (women), not only her body. Certainly it is less aesthetic if the word of mbadha is subtituted by wuto 'your self'. Mbadha'body' in the sentence of Lahaetunggunombadha 'who is the guard of the body' actually refers to wuto'your self'.

The last one as the means of transference is metonymy. It is the use of the name of one thing for that of something else which it associated [11]. The use of metonymy in kabhantican be seen in the example bellow.

1. WaDhalaetindalalo "the calm slim one"

Koetighobandingie "Do not always compare (with the other)"

WaDhalaetindalalo 'the calm slim one' in the first line is an expression of metonymy. It refers to a women that identified by $w a$ as the feminine marker. The women is slim and calm. So she is associated with her body appearance, dhalae 'slim' and her character of tindalalo'calm'.

2. Honest Deception

Semantic deviation through honest deception occurs by the using of litotes, hyperbole, and irony [6]Litotes is a figure of speech of understatement, refers to quantity, quality, measurement, size, or capacity by saying too little. Pay attention to under example.
1. Olusendidinowatu
"the cloud a slice there"
Hadaenoinakumo
"May be it is my mother"

The expression of litotes is found in the first line, olusendidino 'the cloud a slice". Certain object or thing that is modified by a slice is usually bread or butter; a slice of bread or a slice of butter. But in kabhanti number (11) above, sendidino 'the slice' modifies or explains olu "the cloud". The use of sendidino "the slice" to state the size of olu "the cloud' here is too little.

Hyperbole is the opposite of litotes. If litotes states too little, hyperbole states too much from the real condition of quality, size, capacity, or any thing else. Keraf [22] argues that hyperbole is the way of expressing idea by stating excessively form the real situation or measurement. The using of hyperbole in kabhanti can be seen in the example bellow.

\section{Mbasitiekulahae "Who is my relatives" Lagisomatengkanau "Will die for me"}

Hyperbole expression in kabhanti number (11) above is found in the second line. Somatengkanau 'will die for me' actually is the expression that states situation excessively. Somatengkanau'will die for me' refers to the sentence in the first line mbasitieku 'my relatives'. The expression in the first line is a question, identified by the question word of lahae 'who'. Semanticly the expression contains expectation that there is a member of relatives will sincerely help the singer as the subject. But the expectation is expressed by using hyperbole. The meaning of 'sincerely help me' is stated with somatengkanau'will die for me'.

Irony is a figure of speech that states something contrast to the real meaning. It is also states two opposite things. In kabhanti, the using of irony can be seen in the following example.

\section{Kakoadhonowuraha "How beautiful the appearance is" Kadeadhonombirita "How bad the news is"}

Two sentences of kabhanti lyrics in number (13) above are contrast each other. Kakoadhono'how beautiful' in the first line is contrast to kadeadhono 'how bad' in the second line. Semanticly the lyrics of kabhanti above state irony of a certain women whose a beautiful face but unfortunately her habit is not good and the news about her is negative. 


\section{4bConclusion}

Phonological, grammatical, and semantic deviations in the lyrics of kabhantigenerate the existence of aesthetic sense that make the language style of kabhanti perceived more aesthetic and artistic than the conventional style. Phonological deviation is achieved by phonemic addition; there are three phonemes appear at the beginning and middle of words; they are nasal alveolar of $n / \mathrm{n} /$, nasal velar of $n g / \mathrm{h} /$, and fricative alveolar of $m / \mathrm{m} /$. Grammatical deviation occurs in syntacticlevel, it is inversion. Semantic deviation takes place through transference and henost deception. Transference is achieved by the using of figurative languages of metaphor, synecdoche, and metonymy; whereas honest deception occurs by the using of litotes, hyperbole, and irony.

\section{Reference}

[1] Aderlaepe, Sejarah dan Kebudayaan Muna. Jakarta: Daulat Express, 2017.

[2] Aderlaepe, Kumpulan Nyanyian Rakyat Daerah Muna. Raha: BadanPerencanaandan Pembangunan Daerah KabupatenMuna Sulawesi Tenggara, 2016.

[3] R. Finnegan, Oral Traditions and Verbal Arts: A Guide to Research Practices. New York: Routledge, 1992.

[4] W. J. Ong, Orality and Literacy. New York: Methuen, 1982.

[5] N. . Leech, Stylistic in T.A. van Dijk (Ed.) Discourse and Literature. Amsterdam: John Benjamins, 1985.

[6] X. and S. M. Li, "A stylistic Study on the Lingusitic Deviation in E.E. Cumming's Poetry," J. Pan-Pacific Assoc. Appl. Linguist., vol. 19, no. 2, pp. 23-54, 2015.

[7] P. Verdonk, Stylistics. New York: Oxford University Press, 2002.

[8] A. Teeuw, Sastra dan Ilmu Sastra: Pengantar Teori Sastra. Jakarta: Peberbit Duni aPustaka Jaya, 1984

[9] S. Mills, Feminist Stylistics. London and New York: Routledge, 1995.

[10] H. Ardianto, "KabhantiWuna Media KomunikasiTradisionaldanTantangannya di Era Globalisasi," J. Potret Pemikir., vol. 20, no. No. 2 Juli-Desember, 2016.

[11] N. G. Leech, A Linguistic Guide to English Poetry. London: Longman, 1969.

[12] Y. Xueyong, A Stylistic Study on Eglish Poetry. Beijing: Science and Publishing House, 2007.

[13] D. Jones, An Outline of English Phonetics. Cambridge: Heffner and Sons Ltd., 1918.

[14] H. and V. Pirnajmuddin, "Linguistic Deviation in Poetry Translation: An Investigation into the English Renderings of Shamalu's Verse," J. Lang. Teach. Res., vol. Vol. 2, no. No. 6, pp. 13291336 ,.

[15] M. . Abrams, The Mirror and The Lamp : Romantic Theory and The Critical Tradition. New York: Holt, Rinehart and Winston, 1976.

[16] Aminuddin, Stilistika: Pengantar Memahami Bahasa dalam Karya Sastra. Semarang: IKIP Semarang Press, 1995.

[17] R. dan A. W. Wellek, Teori Kesusastraan. Translated by Melani Budianta. Jakarta: Gramedia Pustaka Utama, 1995.

[18] R. Van den Berg, A Grammar of the Muna Language. Leiden: Summer Institute of Linguistics, 189AD.

[19] N. Chomsky, Syntactic Structure. Mouton: The Hague Publisher, 1957.

[20] I. N. K. Ratna, Stilistika: Kajian Puitika Bahasa, Sastra, dan Budaya. Yogyakarta: Pustaka Belajar, 2007.

[21] H. et al Alwi, Tata Bahasa Baku Bahasa Indonesia. Jakarta: BalaiPustaka, 2003.

[22] G. Keraf, Gaya Bahasa. Jakarta: Balai Pustaka, 1996. 